\title{
Adapting Stand-Alone Renewable Energy Technologies for the Circular Economy through Eco-Design and Recycling
}

Gallagher, John; Basu, Biswajit; Browne, Maria ; McCormack, Sarah; Pilla, Francesco; Styles, David

\section{Journal of Industrial Ecology}

DOI:

10.1111/jiec. 12703

Published: 01/02/2019

Peer reviewed version

Cyswllt i'r cyhoeddiad / Link to publication

Dyfyniad o'r fersiwn a gyhoeddwyd / Citation for published version (APA):

Gallagher, J., Basu, B., Browne, M., McCormack, S., Pilla, F., \& Styles, D. (2019). Adapting Stand-Alone Renewable Energy Technologies for the Circular Economy through Eco-Design and Recycling. Journal of Industrial Ecology, 23(1), 133-140. https://doi.org/10.1111/jiec.12703

\footnotetext{
Hawliau Cyffredinol / General rights

Copyright and moral rights for the publications made accessible in the public portal are retained by the authors and/or other copyright owners and it is a condition of accessing publications that users recognise and abide by the legal requirements associated with these rights.

- Users may download and print one copy of any publication from the public portal for the purpose of private study or research.

- You may not further distribute the material or use it for any profit-making activity or commercial gain

- You may freely distribute the URL identifying the publication in the public portal ?
}

Take down policy

If you believe that this document breaches copyright please contact us providing details, and we will remove access to the work immediately and investigate your claim. 
Adapting stand-alone renewable energy technologies for the circular economy through ecodesign and recycling

John Gallagher ${ }^{\mathrm{a}, \mathrm{b}, *}$, Biswajit Basu ${ }^{\mathrm{a}}$, Maria Browne ${ }^{\mathrm{a}}$, Alan Kenna ${ }^{\mathrm{a}}$, Sarah McCormack ${ }^{\mathrm{b}}$, Francesco Pilla ${ }^{\mathrm{c}}$, David Styles ${ }^{\mathrm{b}}$

${ }^{a}$ Department of Civil, Structural \& Environmental Engineering, Trinity College Dublin, Ireland

${ }^{\mathrm{b}}$ School of Environment, Natural Resources \& Geography, Bangor University, Wales

${ }^{c}$ School of Architecture, Planning and Environmental Policy, University College Dublin, Ireland

* Corresponding Author. Email address: j.gallagher@tcd.ie

\begin{abstract}
Renewable energy (RE) technologies are looked upon favourably to provide future energy demands and reduce greenhouse gas (GHG) emissions. However the installation of these technologies requires large quantities of finite material resources. We apply life cycle assessment to 100 years of electricity generation from three stand-alone RE technologies - solar photovoltaics (PV), run-of-river hydro and wind - to evaluate environmental burden profiles against baseline electricity generation from fossil fuels. We then devised scenarios to incorporate circular economy improvements targeting hotspots in systems' life cycle, specifically (i) improved recycling rates for raw materials and (ii) the application of eco-design. Hydro presented the lowest environmental burdens per kWh of electricity generation compared with other RE technologies, owing to its higher efficiency and longer lifespans for main components. Distinct results were observed in the environmental performance of each system based on the consideration of improved recycling rates and eco-design. Circular economy measures produced similar modest savings in already low GHG emissions burdens for each technology, while eco-design specifically had the potential to provide significant savings in abiotic resource depletion. Further research to explore the full potential of circular economy measures for RE technologies will curtail the resource intensity of RE technologies required to mitigate climate change.
\end{abstract}

Keywords: life cycle assessment; renewable energy; circular economy; recyclability; resource depletion; eco-design.

\title{
1 Introduction
}

The expansion of the global renewable energy (RE) sector has been evident in recent years, (REN21, 2014), improving energy security by decreasing dependency on finite fossil fuels and delivering climate change mitigation. As the EU Directive 2009/28/EC drives growth in the RE 
sector (EU, 2009), significant investment is required to achieve targets aiming to double renewable electricity generation from 3,500 TWh to 7,000 TWh by 2035 (IEA, 2014). The combination of technological advancements, savings from lean product manufacturing and government incentivisation are some of the key factors that have driven continued investment in the sector (IRENA, 2015). The underlying reason for RE deployment has been a commitment to address climate change by reducing greenhouse gas (GHG) emissions (EEA, 2015). For this reason, further growth will take place in this century, as expansive opportunities of green energy are yet to be exploited.

Based on the expected growth in the RE sector, it is realised that significant quantities of energy and raw materials will be required to manufacture and maintain these systems. Previous research compared that higher material contributions for RE technologies (e.g. iron/steel, copper, etc.) compared to conventional fossil fuel generation systems (Hertwich et al., 2015, Kleijn et al., 2011). Not only are large quantities of resources required, but in some cases these can be rare earth metals (Elshkaki and Graedel, 2013). Previous reporting of the environmental impacts for RE projects has typically focused on carbon (Donnelly et al., 2010, Rule et al., 2009, Varun et al., 2009, Akella et al., 2009). However, the depletion of abiotic resources has received more interest in recent years (Klinglmair et al., 2014, Gallagher et al., 2015b), and this also needs to be addressed in the renewables sector. Due to the emissions attributed to fossil-fuel electricity generation, the overall carbon footprint of RE technologies is significantly lower than for fossil-fuel generation over the respective systems lifespan (Hertwich et al., 2015). However, the resource depletion burdens of hydropower installations for example are higher than for fossil-fuel power plants, and small-scale hydro systems generate greater resource depletion burdens (Gallagher et al., 2015a) than larger hydro installations (Hertwich et al., 2015), per kWh of electricity generated. Therefore, addressing improvements in resource performance for RE technologies at all scales should be considered, as future RE will be generated from a range of installation types and sizes.

\subsection{Circular economy}

The transition to a circular economy sets out a pathway to ensure future environmental and economic security (EC, 2015b). In the context of achieving global energy security through RE systems, implementing these technologies with a circular or 'cradle to cradle' emphasis as presented in Figure 1, as opposed to the traditional linear or 'cradle to grave' approach (EC, 2014, Ellen MacArthur Foundation, 2013), has not been given sufficient attention. Indeed, it is positive that there are roadmaps for the circular economy (EC, 2015a) and a RE future (IRENA, 2016), even if there is so far limited joint-thinking for merging these two concepts. 


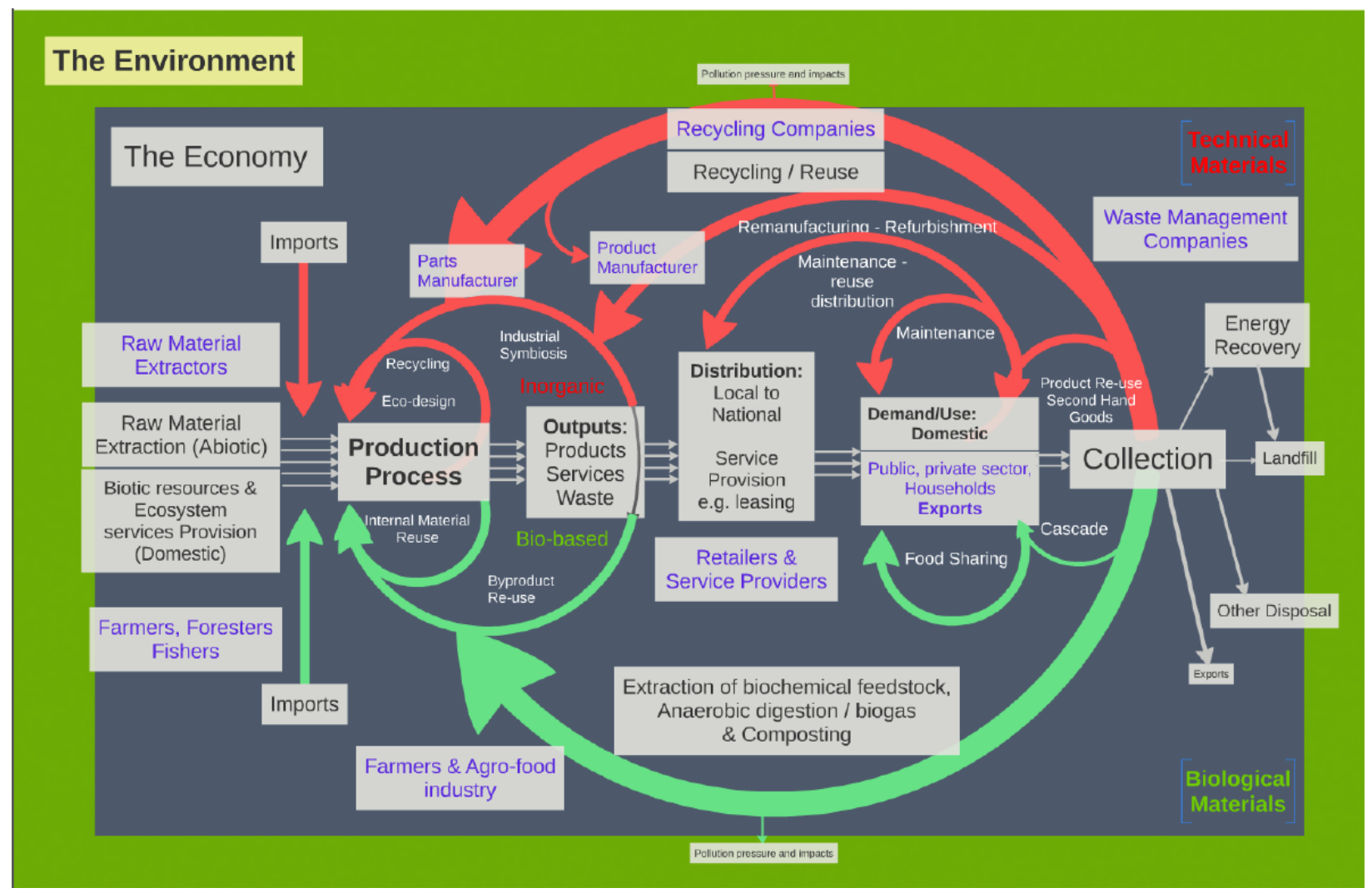

Figure 1. Illustration of the transition of value chains to achieve a circular economy (EC, 2014).

As shown in Figure 1, there are several opportunities to improve the circular performance of RE systems: the application of eco-design to reduce resource demands, driven by EC Directive 2009/125/EC (EC, 2009); developing high-standard maintenance and reuse procedures; adopting better remanufacturing and retrofit/refurbishment practices; and improving the recyclability and reusability of materials. In this study, two areas gain particular focus: (i) improvements in recycling rates at the end of installation life spans; and (ii) eco-design applied in the early design process for each RE system. The concept of 'dematerialisation' is considered to reduce consumption by increasing material efficiency, promoting material shifts and increasing the recycling of products (van der Voet et al., 2004, Cooper et al., 2016). Furthermore, ten Brink et al. (2014) recently highlighted that reuse and recycling is the most notable contributor to achieving a circular economy. In addition, eco-design can have added value by promoting energy efficiency in manufacturing and operation (Toxopeus et al., 2015, McDonough and Braungart, 2010). Both these strategies support the provision of sustainable development of RE technologies in the context of a circular economy (Sauvé et al., 2015).

\subsection{Research objective}


In this study, three RE technologies - solar PV, run-of-river hydro and wind - are examined using LCA to compare their performance in the context of the circular economy, specifically the potential to reduce the environmental impacts through improved recyclability rates and eco-design measures. The findings of the LCA will present the environmental impacts for the most common size of installation of each technology over recent years in the UK and Ireland. By considering a 'cradle to cradle' life cycle, opportunities to identify environmental burden hotspots in current RE systems can provide future guidance on deploying next generation RE technologies as low carbon and resource efficient systems. The LCA will assess specific measures that promote circular economy opportunities to allow each stand-alone RE technology to continue generating electricity over the next 100 years. A breakdown of material and component contributions required to deliver each stand-alone installation will be examined to quantify the potential for improvements through the use of materials more efficiently, using less and/or alternative materials in future iterations in design of these RE technologies. Considering the circular economy agenda presented by ten Brink et al. (2014), it is important to identify the potential that eco-design of system components as well as recyclability and reuse of materials can have on the future of low-carbon technologies. The findings will further our understanding of how to improve RE technologies in line with the circular economy.

\section{Summary of methods}

This paper is supported by a detailed methodology provided in the Supplementary Information (S.I.). The methods and materials section in the S.I. presents the overall goal and scope of this LCA study. This includes an outline of the impact categories selected for examination, the referencing system and methodology for comparing the performance of each RE technology is presented, and a rationale for applying a 'cradle to cradle' system boundary conditions to capture the circular economy performance are discussed. In addition, details regarding the choice of cutoff threshold applied and information relating to comparing the results to marginal grid electricity are explained. A detailed overview of the assumptions for improvements in recycling rates over the next one-hundred years for the key materials in each RE system is presented in Table S4 in S.I., with low, medium and high range values predicted at an interim and end date. This section also includes case study descriptions (Table S6 in S.I.), detailed life cycle inventories and opportunities for applying recycling and eco-design (supported by Table S7-S12 and Figure S1$\mathrm{S} 3$ in S.I.) to each of the three stand-alone RE installations of solar PV, run-of-river hydro and wind. 
The results section of the S.I. presents the baseline scenario for each RE technology and provides a comparison of the normalised contributions of these installations with marginal grid electricity. Further details are shown in the results section that explore the potential of improved recycling rates and the application of eco-design to each RE technology and compared these results to the baseline scenario. A summary of these results are presented in the paper, with the S.I. providing an additional breakdown of details relating to the impact of each measure on the overall environmental burden of the three stand-alone RE systems.

\section{Results}

\subsection{Baseline scenario}

\section{Contribution analysis of RE technologies over 100 year lifespan}

The environmental impacts for the baseline scenario for each RE technology are compared to marginal electricity, per kWh of electricity, from a gas plant in Figure 2. For the baseline scenario, the GWP, FRDP and AP burdens were significantly lower for each of the three representative renewable technologies when compared to marginal electricity from a gas plant. This was due to the high burden associated with the combustion of natural gas throughout the 100 year operational period. However, the normalised life cycle environmental burdens were higher for ARDP for all three RE technologies, higher for HTP for solar PV and wind, and higher for AP for wind, compared with reference electricity from the gas power plant. The exceedance of the ARDP burden for each RE system in comparison to the reference gas plant was due to the high proportion of raw materials embodied in the infrastructure of the RE technologies used to generate each $\mathrm{kWh}$ of electricity. The high HTP and AP burdens for solar PV and wind were largely due to steel or aluminium requirements. 


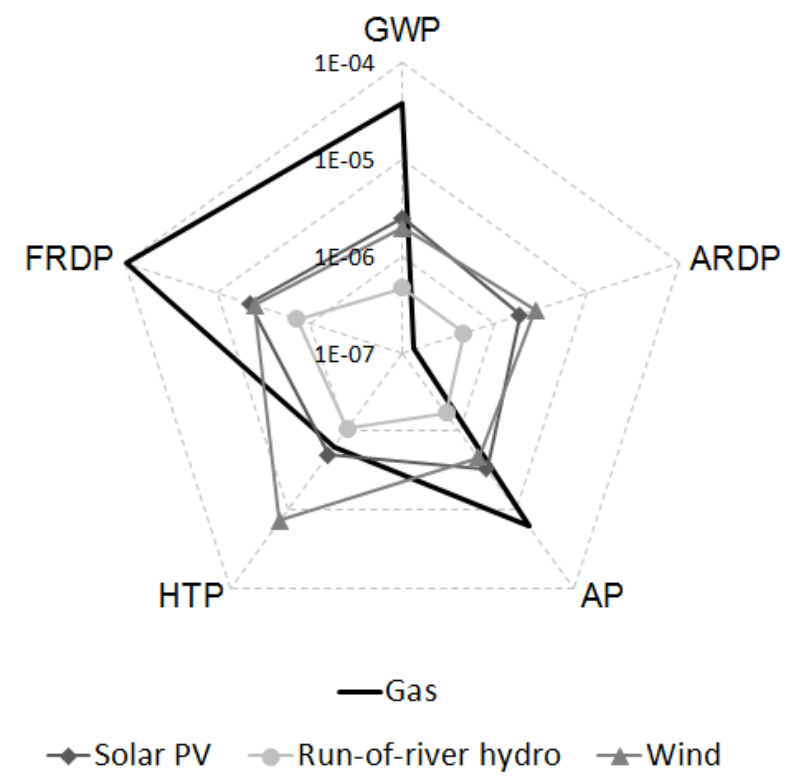

Figure 2. Normalised contributions of baseline scenario over 100 year lifespan for representative standalone RE installations and marginal grid electricity sourced from a gas power plant (data normalised to allow for clear comparison between electricity sources, see S.I. for specific details of normalisation methodology). 

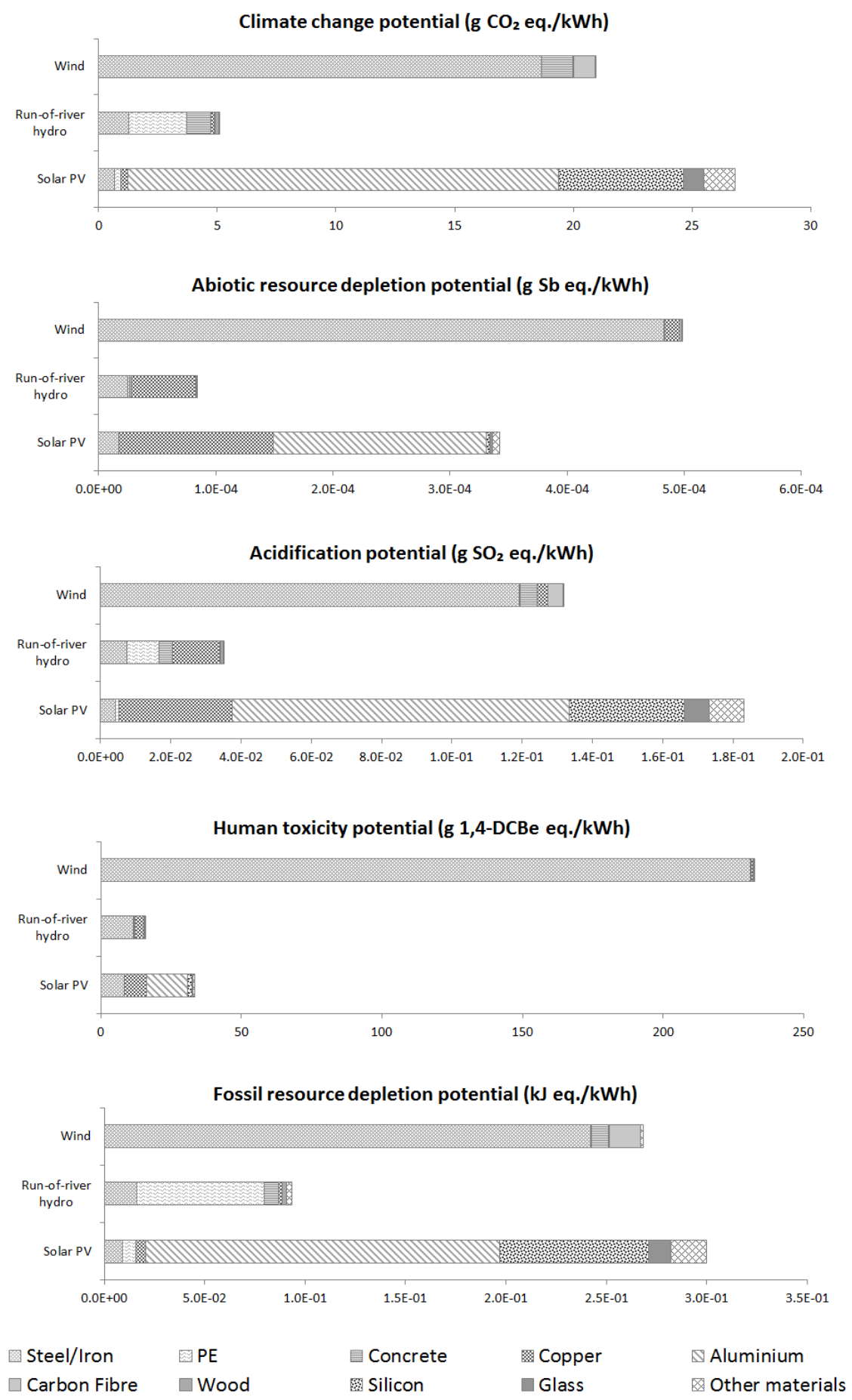

Figure 3. Breakdown of material contributions to baseline environmental burden categories for each stand-alone RE technology (expressed per $k W h$ generated over planned 100 year lifespan).

It was also noted that future iterations of deployment of RE technology would incur lower environmental impacts linked to transportation and manufacturing due to increased RE is the grid electricity mix. Over the 100 year lifespan results, increased RE in the grid electricity mix reduced almost all environmental burden categories examined in this study, with the exception of ARDP (which increased by $3.5 \%$ to $7.2 \%$ ) due to the increased demand of resources to deploy these 
technologies. This highlights the need for improved efficiency in the use of raw materials, and the importance of circular economy measures such as those considered in this study.

Figure 3 presents material contributions to life cycle environmental burdens of electricity generation by each RE technology, expressed per kWh generated over the planned 100 year lifespan. The environmental intensity of electricity generation by each RE system over technologyspecific lifespans is compared with natural gas electricity generation in Figure S4 in S.I. These results represent baseline environmental burdens for each technology used to target and benchmark potential circular economy measures. The baseline scenario for each technology incorporates current estimates on recycled material content in the initial installation, assuming this remains constant for future generations of each RE technology over the next 100 years (outlined in the recycled materials section in S.I.).

Current and future manufacturing and construction, transportation, on-site works and operation and maintenance works were accounted for in the deployment of each generation of RE technology over the next 100 years by incorporating future energy trends and associated environmental burdens into these processes (details provided in marginal grid electricity sections in S.I.).

\subsection{Circular economy impacts on RE technologies}

Results comparing baseline environmental burdens with scenarios of improved recycling rates and eco-design measures for each stand-alone RE technology are presented in the following sections (see S.I. for additional details).

\section{Solar PV}

Circular economy measures to reduce the overall environmental burdens of a stand-alone solar PV installation include improved recycling rates and the application of eco-design (Figure S6 in S.I.). In terms of recycling, most materials (aluminium, glass, silicon and wiring) were considered recyclable for the solar PV installation. Improvements in recycling rates for future generations of solar PV installation translated into reductions in the environmental intensity of solar PV electricity ranging from less than $1 \%$ for ARDP to $4 \%$ for FRDP, if only minimum improvements in recycling rates are achieved, while savings of between of $1 \%$ for ARDP and $11 \%$ for FRDP are possible if maximum recycling rates are delivered. The application of eco-design measures offered further reductions across all burden categories examined, with a minimum reduction of $5 \%$ for ARDP and up to $12 \%$ for FRDP. These measures included a thinner frame and solar cell. Eco-design savings were between up to 1.5 greater than savings achieved by maximum recycling rates across four of the five categories, and over four times greater for the FRDP category. Eco-design and improved 
recycling rates may be applied in tandem to reduce the environmental burdens of stand-alone solar PV installations.

\section{Run-of-river hydro}

Detailed results from improved recycling and the application of eco-design to run-of-river hydro installations are presented in Figure S7 and S.I.). Higher recycling rates can reduce the environmental burdens of this RE technology by less than 1\% for ARDP and between 2-8\% for FRDP, if low and high recycling rates are achieved, respectively. This arises from recycling of different metals in the turbine, generator and electrical equipment. Results for HTP were similar to those for ARDP, whilst AP and GWP showed modest savings of 3\% and 5\% if high recycling rates are achieved. Eco-design reduced the quantity of concrete used in construction through substitution with greener materials such as wood, and reduced the quantity of steel used the turbine and powerhouse roof. The potential impact of eco-design measures presented was half that of what could be achieved through achieving maximum improvements in recycling rates for FRDP. However, eco-design led to GWP and AP savings 1.3 times greater than those achieved by recycling, and ARDP and HTP savings 7.7 and 15.1 times greater, respectively, than those achieved by increased recycling for the hydro installation. This translated into burden reductions of between $4 \%$ (FRDP) and 10\% (HTP) for electricity generation following eco-design of hydropower installations.

\section{Wind}

Circular economy measures can also be applied to larger scale RE technologies such as standalone wind turbines. The results from applying these measures are presented in S.I. in Figure S8. Improvements in future recycling rates showed the potential to reduce the environmental burdens of wind-generated electricity by less than $1 \%$ for HTP and between $1 \%$ and $6 \%$ for GWP and FRDP where minimum or maximum recycling rates are achieved, respectively. This was primarily linked to recycling the large quantities of steel and other heavy metals used in the construction of wind installations. Applying eco-design to this RE technology offered further reductions for all environmental burden categories, with a minimum reduction of $6 \%$ for GWP and up to $29 \%$ for HTP. Maximum recycling achieved a marginally greater saving than eco-design for GWP, $6 \%$ versus 5\%, while eco-design achieved greater savings for all other burden categories examined. The savings considered by substitution the steel tower with a hybrid concrete and steel tower structure helped extend the lifespan of the tower and the use of alternative material. In comparison to achieving maximum recycling rates, the impact of the hybrid tower demonstrated it could have 
2.2-2.4 times the impact of reducing the AP and FRDP burdens, while the hybrid tower had significantly larger reductions of 20.6 and 50.4 times more for ARDP and HTP, respectively.

\section{Discussion}

\subsection{Circular economy measures}

Increased recycling rates

Considering higher recycling rates in the future, and assuming that RE system components are recycled at the end of their lifespan in line with these prevailing rates, the environmental burdens of electricity generation from the three studied RE technologies could be reduced significantly. Increased recycling rates were more significant for GWP and FRDP burdens than for ARDP and HTP burdens for all three stand-alone RE installations. Increased recycling was shown to have the most notable benefit for Solar PV across all environmental burdens, followed by smaller benefits for run-of-river hydro and wind, with the smallest benefit for hydro across all impact categories with the exception of FRDP.

Questions have arisen over the recyclability of materials used in some other types of solar PV installations (Elshkaki and Graedel, 2013), as cells with rare earth metals deliver higher efficiencies yet present potential additional challenges for recycling materials as opposed to poly$\mathrm{Si}$ or organic materials. This is an area where uncertainty exists with regards to future capabilities to recover and recycle small quantities of these valuable materials in technologies such as solar PV cells.

In the case of run-of-river hydro and wind, increasing recycling rates for concrete in the weir or intake, or in steel reinforced foundations, is more challenging owing to restricted access to these components e.g. in a river or under ground level. However, a longer lifespan and lower material intensity for run-of-river hydro systems result in better comparative environmental performance. Future performance could be enhanced by reusing the weir and intake in future refurbishments (Gallagher et al. 2015b). Extending the lifespan of wind turbine components to realise similar savings would require technological improvements such as more effective damper devices or advanced control systems (Fitzgerald et al., 2013, Schlipf et al., 2013).

Prevailing trends of increasing recycled content in the main materials, especially metals, used in RE installations are likely to ameliorate the environmental hotspots of material use and human toxicity associated with RE technologies, enhancing their environmental sustainability. There remain a few challenges to ensure that materials used in RE installations can continue through recycling loops at the end of $\mathrm{RE}$ installation lifespans in the future circular economy, to further reduce these environmental hotspots. 


\section{Application of eco-design}

In addition to recycling materials in RE technologies, the application of eco-design measures at the design stage for these systems can improve their circular economy performance. Eco-design was shown to have a greater impact on reducing the environmental burden of each technology than achieving maximum future recycling rates, with the exception of FRDP for a run-of-river hydro and GWP for the wind turbine installation. The most substantial results were observed for the ARDP and HTP impact categories for the wind turbine, while solar PV reductions were dominated by GWP, AP and FRDP, and the savings for the hydro installation were linked to reductions in GWP and HTP.

Eco-design considerations for solar PV focused on using less material, such as a thinner frame design or thinner cell, translating into life cycle savings that did not affect end-of-life recyclability. A modular approach to designing solar PV systems can ensure the direct reuse of components such as the aluminium frame so that recycling is not required, further improving the environmental performance of this technology which currently exhibits higher burdens than other RE options.

For the run-of-river installation, eco-design opportunities focused on alternative material selection that presented GHG mitigation opportunities, and could be associated with other sustainability benefits if materials are locally sourced. The overall improvements in the performance of the hydro installation were due to multiple, small eco-design opportunities.

Significant reductions in the ARDP and HTP burdens of wind-generated electricity could be achieved through eco-design solutions including the use of a steel and concrete hybrid tower. This led to lower overall burdens, but may conflict with the circular economy ethos as concrete is not an easily recyclable material. However, this measure extends the lifespan of the tower as the concrete tower component has a better resistance to the structural stresses observed in steel towers. This is turn has the potential to extend the lifespan of the turbine blades made of composite and unrecyclable material, by reducing vibrations and minimising the accumulation of fatigue damage (Manwell et al., 2010).

For typical sizes of these three RE systems, eco-design can play an important role in reducing environmental impacts and delivering circular economy goals.

\subsection{Carbon footprints vs. resource depletion}

Carbon (GWP) and resource (ARDP) burdens have previously been compared for RE technologies by Gallagher et al. (2015b), where some divergence trends were highlighted for strategies that focus solely on further reducing the carbon footprint of RE technologies. Focusing on both of these 
impact categories, distinct results were achieved through improving material recycling rates and promoting eco-design for each RE system. The greatest overall GWP reduction of $20 \%$ was found for the solar PV installation by combining eco-design with maximum recycling rates. GWP savings were significantly smaller for run-of-river hydro and wind turbine installations. In contrast, the role of recycling and eco-design reduced the ARDP burden for a wind installation by $28 \%$, in comparison to small reductions of $7 \%$ for solar PV and 5\% for hydro. This highlights that there is some complementarity between efforts to further reduce the already low carbon footprint of RE electricity and to reduce resource depletion, but that effective targeting of environmental hotspots requires a specific focus on resource depletion to improve the performance of these systems within the circular economy.

Improved recycling rates and eco-design measures have joint roles to play in reducing the environmental burdens of RE technologies, but effective mitigation will require different combinations of measures for each technology. For all three RE technologies, recycling and ecodesign presented relatively similar improvements for GWP. Eco-design provided 20-32\% greater GWP savings than improved recycling for solar PV and run-of-river hydro, yet the opposite was observed for wind as recycling presented $21 \%$ more savings than eco-design. The results for ARDP were more prominent as eco-design delivered the majority of savings, with more than four or five times that of achieving maximum recycling rates for solar PV and run-of-river hydro respectively, and over twenty times more than recycling for wind.

The circular economy measures examined in this study are not exhaustive in relation to the potential opportunities that exist for these three RE technologies, yet the study does highlight the importance of considering RE technology deployment from a circular economy perspective in order to mitigate environmental hotspots of these low-carbon sources of electricity. In general, there is the need for more emphasis on resource use, alongside carbon footprints, when developing these systems, as future generations of RE installations will need to be manufactured in a world of limited natural resources.

\section{Conclusions}

Three stand-alone RE technologies-solar PV, run-of-river hydro and wind - of varying sizes were examined, representing the most common deployment formats in Ireland and the UK over recent years. Results are specific to these sizes of installation, but reflect the typical challenges of addressing the impact of improved recycling rates and eco-design for each RE technology. This paper demonstrates that, from a life cycle assessment perspective, there is scope to improve how 
these technologies perform in the context of the circular economy, through modified design and manufacturing processes.

The baseline scenario outlined in this paper presents "typical" life cycles of three key RE technologies, with the run-of-river hydro installation incurring the lowest environmental burdens owing to its lower material intensity per unit installed capacity and longer lifespans for main components. However, despite generating electricity with a low GHG intensity, our expanded LCA highlighted that current deployment of all these technologies is inefficient with respect to high dependence on finite resources - posing a challenge to their sustainability.

By examining two categories of circular economy measures, improvements in recycling rates and the adoption of eco-design, it is evident that significant reductions in the environmental intensity of these RE technologies can be achieved. The comparative efficacy of improving recycling rates and applying eco-design varies depending on whether the traditional focus on carbon reduction is maintained, or whether to the environmental hotspot of resource depletion is prioritised.

The findings demonstrate hotspots in each RE technology for different environmental burden categories, and demonstrate the plethora of options available to ensure that future development of RE technologies adheres to circular economy principles, helping to close resource loops and make wise use of our limited resources. However, further research is required to examine the full potential of a circular approach to renewables to ensure we have future energy security in a lowcarbon and resource efficient society.

\section{References}

AKELLA, A. K., SAINI, R. P. \& SHARMA, M. P. 2009. Social, economical and environmental impacts of renewable energy systems. Renewable Energy, 34, 390-396.

COOPER, S., SKELTON, A. C. H., OWEN, A., DENSLEY-TINGLEY, D. \& ALLWOOD, J. M. 2016. A multi-method approach for analysing the potential employment impacts of material efficiency. Resources, Conservation and Recycling, 109, 54-66.

DONNELLY, C. R., CARIAS, A., MORGENROTH, M., ALI, M., BRIDGEMAN, A. \& WOOD, N. 2010. An assessment of the life cycle costs and GHG emissions for alternative generation technologies. World Energy Congress. Montréal, Canada.

EC 2009. Directive 2009/125/EC of 21 October 2009 establishing a framework for the setting of ecodesign requirements for energy-related products. Official Journal of the European Union.

EC 2014. Scoping study to identify potential circular economy actions, priority sectors, material flows and value chains. Luxembourg: European Commission.

EC 2015a. Roadmap - Circular Economy - Closing the loop. European Commission.

EC 2015b. Roadmap - Circular Economy Strategy - Public Consultation on the Circular Economy. European Commission.

EEA 2015. Renewable energy in Europe - approximated recent growth and knock-on effects. Luxembourg: European Environment Agency. 
ELLEN MACARTHUR FOUNDATION 2013. Towards the Circular Economy Vol. 1: an economic and business rationale for an accelerated transition. Ellen MacArthur Foundation.

ELSHKAKI, A. \& GRAEDEL, T. E. 2013. Dynamic analysis of the global metals flows and stocks in electricity generation technologies. Journal of Cleaner Production, 59, 260-273.

EU 2009. Directive 2009/28/EC of 23 April 2009 on the promotion of the use of energy from renewable energy sources and amending and susequently repealing Directive 2001/77/EC and 2003/30/EC. In: UNION, T. E. P. A. T. C. O. T. E. (ed.).

FITZGERALD, B., BASU, B. \& NIELSEN, S. R. K. 2013. Active tuned mass dampers for control of in-plane vibrations of wind turbine blades. Structural Control and Health Monitoring, 20, 1377-1396.

GAllAGHER, J., STYleS, D., MCNABOLA, A. \& WILliAMS, A. P. 2015a. Current and future environmental balance of small-scale run-of-river hydropower. Environ Sci Technol, 40, 6344-6351.

GALLAGHER, J., STYLES, D., MCNABOLA, A. \& WILLIAMS, A. P. 2015b. Making green technology greener: Achieving a balance between carbon and resource savings through ecodesign in hydropower systems. Resources, Conservation and Recycling, 105, Part A, 11-17.

HERTWICH, E. G., GIBON, T., BOUMAN, E. A., ARVESEN, A., SUH, S., HEATH, G. A., BERGESEN, J. D., RAMIREZ, A., VEGA, M. I. \& SHI, L. 2015. Integrated life-cycle assessment of electricity-supply scenarios confirms global environmental benefit of lowcarbon technologies. Proceedings of the National Academy of Sciences, 112, 6277-6282.

IEA 2014. World Energy Outlook 2014 - Executive Summary. Paris: International Energy Agency.

IRENA 2015. Renewable Power Generation Costs in 2014. International Renewable Energy Agency.

IRENA 2016. Roadmap for a Renewable Energy Future. 2016 Edition ed.: International Renewable Energy Agency.

KLEIJN, R., VAN DER VOET, E., KRAMER, G. J., VAN OERS, L. \& VAN DER GIESEN, C. 2011. Metal requirements of low-carbon power generation. Energy, 36, 5640-5648.

KLINGLMAIR, M., SALA, S. \& BRANDÃO, M. 2014. Assessing resource depletion in LCA: a review of methods and methodological issues. The International Journal of Life Cycle Assessment, 19, 580-592.

MANWELL, J. F., MCGOWAN, J. G. \& ROGERS, A. L. 2010. Wind energy explained: theory, design and application, John Wiley \& Sons.

MCDONOUGH, W. \& BRAUNGART, M. 2010. Cradle to Cradle: Remaking the Way We Make Things, Farrar, Straus and Giroux.

REN21 2014. Renewables 2014 Global Status Report. ISBN 978-3-9815934-2-6 ed. Paris.

RULE, B. M., WORTH, Z. J. \& BOYLE, C. A. 2009. Comparison of life cycle carbon dioxide emissions and embodied energy in four renewable electricity generation technologies in New Zealand. Environ Sci Technol, 43, 6406-13.

SAUVÉ, S., BERNARD, S. \& SLOAN, P. 2015. Environmental sciences, sustainable development and circular economy: Alternative concepts for trans-disciplinary research. Environmental Development.

SCHLIPF, D., SCHLIPF, D. J. \& KUHN, M. 2013. Nonlinear model predictive control of wind turbines using LIDAR. Wind Energy, 16, 1107-29.

TEN BRINK, P., RAZZINI, P., WITHANA, S. \& VAN DIJL, E. Towards a circular economy in the EU - Priorities and options to move forward. 7 May 20142014 Brussels. IEEP.

TOXOPEUS, M. E., DE KOEIJER, B. L. A. \& MEIJ, A. G. G. H. 2015. Cradle to Cradle: Effective Vision vs. Efficient Practice? Procedia CIRP, 29, 384-389.

VAN DER VOET, E., VAN OERS, L. \& NIKOLIC, I. 2004. Dematerialization: Not Just a Matter of Weight. Journal of Industrial Ecology, 8, 121-137. 
VARUN, PRAKASH, R. \& BHAT, I. K. 2009. Energy, economics and environmental impacts of renewable energy systems. Renewable and Sustainable Energy Reviews, 13, 2716-2721. 